\title{
LIBERTAD Y ALTERIDAD, HACIA UNA FUNDAMENTACIÓN ÉTICA Y EDUCATIVA DEL CUIDADO AMBIENTAL.
}

\section{FREEDOM AND OTHERNESS, TO AN ETHICAL AND EDUCATIONAL FOUNDATION FOR ENVIROMENTAL CARE.}

\author{
Yolothxochilt González Oidor Maestría \\ en Educación Universidad La Salle Pachuca \\ yoloth17@hotmail.com \\ Jesús Salvador Moncada Cerón Doctor \\ en Educación Investigador Universidad La Salle México \\ jsmoncada1@yahoo.com.mx
}

\section{Resumen}

El presente ensayo pretende ofrecer una información básica, rigurosa y fundamentada sobre la ética ambiental. Es urgente avanzar en la construcción de una teoría ética que sea capaz de enfrentar los problemas planteados al hombre de hoy por la extensión y profundidad de su poder sobre la naturaleza. Es necesario afirmar la dignidad ontológica de los seres vivos y la capacidad real de transformación o de elaboración de las posibilidades que nos ofrece la naturaleza.

Palabras claves: ética, naturaleza, libertad, alteridad, responsabilidad.

\section{Summary:}

This essay pretends to offer basic, severe and supported information about environmental ethics. It is urgent to make progress on the construction of an ethical theory able to face the problems set out on today's human beings because of the extension and deepness of their power over nature. It is necessary to state the ontological dignity of living beings and the actual capacity of transformation or production of the possibilities that nature offers us.

Key words: ethics, nature, freedom, otherness, responsibility.

Los valores son la roca sobre la que se construye la sociedad; en la vivencia de dichos valores se juega el valor de la

\section{Introducción}

Las Naciones Unidas, frente a la gravedad y urgencia de los problemas ambientales, instituyeron una "Década de la Educación para un futuro Sostenible" (2005-2014), designando a la UNESCO como el órgano responsable de su promoción. Vivimos una emergencia planetaria, con enormes problemas relacionados entre sí: la contaminación y degradación de los ecosistemas, la contaminación, el agotamiento de los recursos naturales, la pérdida de la diversidad biológica. Los indicadores son 
alarmantes, dejan poco margen de tiempo para los cambios necesarios, algunos establecen como fecha límite el año 2030, a partir de ahí el sistema Tierra ya no estará garantizado. Cada día desaparecen para siempre 10 especies de seres vivos; desde la época de la desaparición de los dinosaurios, 65 millones de años atrás, nunca se ha visto un exterminio tan rápido. A partir de 1972 la desertificación en el mundo es equiparable a todas las tierras cultivables de India y China, de 1950 a la fecha se ha talado la mitad de las selvas, la deforestación arrasa 13 millones de hectáreas por año, las inmensas reservas de agua, formadas a lo largo de millones de años, han sido sistemáticamente bombeadas y están próximas a agotarse, probablemente las próximas guerras sean por fuentes de agua potable. Otra amenaza es el calentamiento creciente de la Tierra, es el así llamado efecto invernadero. La naturaleza ya no aguanta más su depredación, si no cuidamos el planeta, partes de la biosfera las ponemos en grave riesgo de destrucción y con ello, inviabilizar la propia vida del planeta.

Se necesitan cambios de hábitos humanos frente al planeta, vivir con la naturaleza y no a costa de la naturaleza. Los educadores, en general, no estamos prestando suficiente atención a esta situación pese a llamamientos como los de las Cumbres de la Tierra (Río 1992 y Johannesburgo 2002) y los Foros Mundiales. Hay que llegar a un compromiso para que toda la educación desde el preescolar hasta los posgrados, presten más atención a la situación del mundo, con el fin de proporcionar una percepción de los problemas ambientales y de fomentar actitudes y comportamientos favorables para el logro de un futuro sustentable. En el informe de la ONU "Objetivos del desarrollo del Milenio" (2009), Ban Ki-Moon Secretario General señala,

"ha llegado la hora de llevar a cabo los cambios estructurales que son necesarios para avanzar más decididamente hacia un desarrollo y sostenibilidad más equitativos y hacer frente a la crisis climática". La palabra "sostenibilidad" proviene de la biología y la ecología. Significa capacidad que un ecosistema tiene de incluir a todos, de mantener un equilibrio dinámico que permita la subsistencia de la mayor biodiversidad posible, sin explotar ni excluir (Boff, 2006).

La ética ambiental nos hará converger una tarea crítica pedagógica para reconstruir el sentido verdadero de la relación del ser humano con la naturaleza. La positivización de las leyes tiene que ser compatible con las leyes éticas. Así como no hay una única imagen científica del mundo que corresponda a lo que el mundo es en sí mismo, tampoco existe una única imagen ética del mismo. Pero esto está lejos de ser una concesión al relativismo. Desde Kant (traducido en 1991), la objetividad dejó de ser la correspondencia de nuestros juicios con lo que el mundo es en sí mismo. La distinción entre hecho y valor no implica que sólo los hechos puedan ser objetivos. Hechos y valores se asemejan en esto: por un lado, son 
construcciones que nos esforzamos por hacer y defender, y por otro lado, el mundo, la cotidianidad de la vida y las dificultades que surgen de nuestra condición humana nos obligan a revisarlas permanentemente.

Existen diversas imágenes científicas del mundo, y de igual manera hay una gran diversidad de posturas éticas que podemos conocer; de unas decimos que son mejores que las demás y por ello las preferimos, y de otras manifestamos que son menos acertadas y por esta razón las criticamos o las desechamos. La paradoja consiste en que sea como fuere, de hecho vivimos en un mundo y en una sociedad con valores y modos de comportamiento que aceptamos o rechazamos. De la pregunta ética: ¿qué debemos hacer?, ninguno nos escapamos.

Desde Sócrates hasta hoy, la preocupación de los pensadores respecto al diálogo entre ética y ciencia, se podría sintetizar en la búsqueda de la esperanza y del sentido de la vida humana (Gómez, 2010). La ética del cuidar, como todo discurso ético, no es un discurso descriptivo, sino prescriptivo. Una cosa es lo que es la realidad tal y como se observa en la vida práctica y, otra cosa es lo que debería ser. La ética, como tal, no trata del ser, como la ontología; ni del ser humano, como la antropología; sino del deber ser; es decir, de lo que podría llegar a ser el mundo si los humanos rigiéramos nuestras vidas a partir de unos principios justos. La ética se refiere a lo óptimo, a lo excelente, mientras que la realidad, en cuanto tal, es ambigua. La ética implica el creer que la realidad puede cambiar; en el fondo, quien discurre éticamente, no cree en la fatalidad de la historia sino en el carácter dinámico y cambiante de la realidad a través y a partir de la voluntad humana. La fe en la libertad es al fin y al cabo, el punto de partida de la ética, lo que Kant denominaba, "el trascendental de la ética" (traducido en 1981, p. 16). La revolución emprendida por Kant respecto de los juicios verdaderos acerca del mundo físico y natural, tiene también su paralelo sobre los juicios que hacemos acerca del comportamiento humano, es decir, respecto de la ética. Kant transformó tanto los fundamentos del conocimiento de la naturaleza, como los fundamentos del conocimiento de conceptos, como la bondad, la maldad, la aprobación, el rechazo o la incertidumbre con que debemos caracterizar algunas de nuestras acciones. El giro Copernicano realizado por Kant (traducido en 1981) respecto de la manera como el hombre conoce el mundo, tendrá una importancia no menos en relación a la manera como el hombre elabora juicios acerca del cómo habrá de comportarse respecto al planeta.

\section{Tarea educativa geocéntrica}

El principio del proceso educativo es la persona como tal, en el sentido cualitativo, porque el ser es un fin en sí mismo y no un medio, y por eso la educación es la posibilidad para que éste logre lo que le hace falta para ser más humano. De ahí que todo proceso educativo se fundamente en 
una visión antropológica específica.

Desde siempre, la educación se ha presentado como una disciplina normativa, como una relación entre personas. Las primeras prácticas educativas no fueron otra cosa más que una manera de conformar los imperativos de la vida cotidiana, e integrar al individuo a la comunidad. A medida que maduraron los grupos y las sociedades, se fueron fijando las técnicas y disciplinas del aprendizaje bajo la autoridad de los más ancianos de la comunidad, ésta fue la educación primitiva.

De aquí pasamos a la educación humanista, que tiene su origen en Platón. Se le llama humanista porque se funda en el hombre mismo, en sus posibilidades, límites y anhelos. Su fin es la realización del sujeto como ser. En este tipo de educación prevalecen las normas sobre el individuo; todo el proceso educativo tiende a la incorporación del sujeto a un modelo reconocido universalmente como bueno. Y se apoya en la definición del hombre como ser ideal y como "homo sapiens", cuya única meta es la de parecerse en lo más posible al modelo del hombre educado, al Hombre (Moncada, 2011a).

La formación del "homo sapiens", se fue substituyendo a lo largo del tiempo, por la formación del "homo faber"; pero ninguna de estas dos concepciones educativas propone al hombre realmente como el principio de su perspectiva, ya que el hombre educado es el resultado alcanzado por una sucesión de actos, regidos por un fin externo; la educación aquí es el premio y término del proceso mismo. En este proceso se observa el deseo de reunir o conjuntar al "homfaber" y el "homo sapiens", para lograr la realización del hombre total (Moncada, 2011b).

El objeto de la educación se presenta actualmente como el desarrollo total y totalizante del ser humano. Esto se fundamenta en la concepción antropológica de Husserl; el hombre es conciencia de algo, es proyección hacia algo, su existencia es un existir (Husserl, traducido en 2009). De alguna forma este desarrollo es intencional, es decir es conocido y querido por el sujeto. De la identificación de este "algo" que mencionábamos anteriormente, del cual el hombre es consciente depende el sentido de la educación, de sus aspiraciones, su inspiración y su devenir, de sus posibilidades y de sus límites.

La educación primitiva identifica este "algo", como el "nosotros". El sujeto educado era conciencia de la colectividad, su fin era encontrarse a sí mismo como miembro de su comunidad. La educación humanística identificó por su parte ese "algo" como el "yo". Como su propio "ego"; el sujeto educado es conciencia de sí, conciencia de su esencia definitiva en términos de razón: el hombre se educa para encontrarse como ser presente. Para descubrir su racionalidad. La educación es en definitiva como un regreso a uno mismo (Moncada, 2011a). 
Si queremos lograr un proceso educativo integrado y total, es preciso volver a definir este "algo" del cual el hombre es conciencia. Y aplicar las dimensiones del sujeto conciencia de sí mismo hacia el mundo, hacia los demás, hacia el cosmos, para poder identificar al ser humano como principio y fin del acto educativo.

a) El hombre como intencionalidad. Para educar al ser, es preciso situarlo en su propia realidad espacio temporal, a que exista en el mundo con los demás; para Heidegger (traducido en 1997) la existencia es un principio dinámico, que implica un diálogo eterno del hombre con el hombre, del hombre con el mundo y del hombre con su Creador.

b) El hombre como ser mundano. El ser humano está inmerso en el mundo, le pertenece. Descubre los significados del mundo poniéndolos momentáneamente entre paréntesis para recuperarlo luego en todas sus dimensiones.

c) El hombre como conciencia de los demás. Como ser intersubjetivo, el hombre es incompleto y aspira a la plenitud, y la busca en las relaciones con los demás para transformar al mundo y en la religación con Dios para ser más. Esta proyección del sujeto hacia los demás se efectúa en el mundo con el que está en relación. No basta con estar en contacto con el mundo, es necesario existir en el mundo con los demás. Sólo así se da la transformación de lo que ya está ahí. El ser en el mundo, es al mismo tiempo un ser-ahí y un serahí-con, es un ser en el mundo con los demás. El ser ahí, sólo es en tanto que tiene la estructura esencial del ser-ahí-con. El tiempo (Heidegger, traducido en 1997) es la dimensión esencial y existencial del ser definido como su propio no-ser-todavía. Por eso vivir es vivir su propia muerte en cada instante, es correr al encuentro de su propia realidad, al encuentro de su futuro, de sus posibilidades. El tiempo es la proyección del todavía-no del hombre; es una sucesión de momentos que se anulan por sí mismos y preparan al momento supremo en el cual el ser ya se conoce (Husserl, traducido en 2009). Todo esfuerzo educativo tiende a formar como si el hombre fuese eterno y tiende a rehusar su temporalidad. Sólo cuando el hombre se sabe y se acepta como ser temporal que peregrina en esta tierra, hace de tal actitud un ser libre.

d) El hombre y el factor cósmico. Los educadores harán lo posible porque los educandos recuperen su dimensión cósmica, puesto que el hombre está inscrito en un marco histórico y mundano. La educación se puede definir como la práctica de la libertad; como dice Freire, el hombre es el fundamento y la condición de posibilidad del acto educativo. La educación debe preparar al hombre a vivir el cambio continuo, educarse es aprender a ser dentro de las condiciones del cambio (Freire, 1969). Esto supone la apertura de la estructura sociocultural del momento hacia una nueva dimensión; es un proceso donde surge una conciencia colectiva de la humanidad y al surgir, ésta se esboza en una cultura planetaria fundada en una simbiosis ecológica; entonces la educación se 
vuelve un proceso de iniciación para un hombre conciencia del universo, quien, vislumbra la existencia de una ecología exterior y de una ecología interior hecha de solidaridad, sentimiento de unidad con el todo, cuidado y armonización. Ambas ecologías están ligadas umbilicalmente. Es lo que se conoce como psicología ambiental o, en la expresión de E. Wilson (2006), como biofilia. Su base no es sólo antropológica sino también cosmológica, pues el propio universo, según reconocidos astrofísicos, como Brian Swimme (1986) entre otros, tendría una profundidad ética. El universo no está solamente formado por el conjunto de objetos, sino por el tejido de relaciones entre ellos, haciéndolos sujetos que intercambian informaciones y se enriquecen. Todo ello configura una verdadera ecología interior, cuyo código de descifrado constituyó una de las conquistas del siglo XX, con Freud, Jung, Adler, Lacan, Hillmann. En último término, el inconsciente colectivo es la expresión de la unidad misma de la Tierra y del universo que irrumpe a través de nosotros, que somos la parte consciente del universo y de la Tierra (Jung, 1970).

Pero, ¿cómo se aprende a ser conciencia del universo? Se intenta encontrar una nueva dimensión para definir al hombre: puede ser la cósmica planetaria; el desarrollo humano debe de encontrar una nueva dinámica interior en un contexto reordenador más amplio de las relaciones fundamentales. Este pensamiento abre la antropología a la dimensión cosmológica, busca y sitúa al hombre en sus relaciones con la Tierra. Aquí el sujeto es conciencia de sí, de los demás, del mundo y del cosmos.

Así, para que el hombre pueda ser más hombre, en su nueva perspectiva geocéntrica, hace falta construir un nuevo sistema de relaciones y prioridades, más que regresar a fórmulas, modelos y sistemas educativos. Hemos de tener en cuenta que el ser humano no es un ser separado del universo, sino más bien, es un modo de ser del universo. Pues el ser es la síntesis del universo, es la microfase del cosmos y el cosmos es la macrofase del hombre. Se establece un sentido de identificación entre las necesidades del ser humano y las necesidades del cosmos. Debe surgir el ser humano cósmico, que no es otra cosa que la persona integrada con el todo y en un verdadero sentido subordinado al todo.

Este paso del antropocentrismo al geocentrismo en la identificación del hombre como tal, conlleva a una formulación de nuevos principios educativos. Si la Tierra según Tomás Berry (2009), es una comunidad auto emergente que se nutre, se gobierna y se educa a sí misma, entonces todos los sistemas particulares deben integrarse en lo que se refiere al ser, a la alimentación, a los procesos de gobierno, a la educación. Asimismo, la principal tarea humana es la de fomentar la intercomunicación de todos los componentes de la comunidad terrestre, del 
planeta. Educarse es aprender a dirigir el proceso evolutivo de la Tierra y a llevar adelante dentro de su propio ser, el proceso evolutivo general. Educarse es aprender a vivir religado al universo al cual pertenece uno en esencia y existencia.

Hay que educarse para proponer la formación futura del hombre-individuo y del hombre-sociedad como parte integrante de la Tierra, como persona cósmica. Para conseguir tal fin hace falta pensar en un programa planetario de la educación, en una espiritualidad planetaria. Rousseau había definido la tarea educativa en términos de recuperación: el hombre es originariamente bueno, la sociedad lo ha corrompido, la educación debe de permitir que el hombre recupere su bondad original, en una forma equivalente dentro del nuevo orden social fundado en la edificación de un contrato social justo (Rousseau, traducido en 1971); sin embargo, tal perspectiva era muy normativa. El esfuerzo educativo propuesto al hombre, en términos de conquista de su propia naturaleza, quedaba centrado en lo meramente humano.

La tarea educativa geocéntrica o planetaria, aunque todavía hoy parezca lejana o utópica, es la que permite encontrar nuestra identidad perdida, el hombre tiene nostalgia de su ser cósmico perdido. Hay que educar para que cada uno pueda volver a su identidad integral, y conjuntamente vuelva a encontrar a los demás. Hay que encontrar un modo de ser fundamental, una manera de ser auténtica, en armonía con nuestra naturaleza y nuestro origen cósmico.

Según Boff (2006), todo lo que existe coexiste. Nada existe fuera del campo de las relaciones, no solamente naturales, sino comprendiendo también naturaleza, mente, cultura y sociedad. En un concepto amplio del ecosistema, tanto el entorno natural como familiar, escolar y social se complementan.

No es la educación la que va a cambiar el mundo. La educación va a cambiar a las personas que van a cambiar el mundo. Necesitamos personas formadas que pasen del paradigma de la conquista del planeta al paradigma del cuidado.

El cuidado es esa condición previa que permite la eclosión de la inteligencia y de la voluntad, es el orientador anticipado de todo comportamiento para que sea libre y responsable, en fin, típicamente humano. El cuidado es un gesto amoroso con la realidad, gesto que protege y trae serenidad y paz. Sin cuidado, nada de lo que está vivo, sobrevive.

\section{Libertad y alteridad}

La crisis crea la oportunidad de ir hasta las raíces de la ética y bajar hasta aquella instancia donde continuamente se gestan valores. La ética debe nacer de la base última de la existencia humana. Esta no reside en la razón como muchos pensadores occidentales siempre han pretendido 
sustentar. La razón no es ni el primero ni el último momento de la existencia. Por eso no explica ni abarca todo. La ética se abre hacia abajo, de donde emerge algo más elemental y ancestral: la afectividad. Como señala Pascal, "el corazón tiene razones que la razón no comprende" (en Lortz, 2008, p. 352). También se abre hacia arriba, hacia el espíritu que es el momento en el que la conciencia se siente parte de un todo, en ella no reside la razón (Logos), sino la pasión (Pathos). Para Goleman (1995) la inteligencia emocional es la base de las relaciones humanas. En efecto, el sentir más profundo del hombre está en el afecto, la emoción y la pasión, que son los que permiten entrar en comunión, sin distancia, con todo lo que nos rodea, principalmente con el ser humano. Por la pasión captamos el valor de las cosas, valor que es el carácter precioso de los seres. Por eso, la experiencia de base no debería de ser: "pienso luego existo" (Descartes, traducido en 2005, p. 49), sino "siento, luego existo". Sólo cuando nos apasionamos vivimos valores y es por valores por los que nos movemos y somos.

Aquí se funda una ética capaz de incluir a todos en la familia humana. Esa ética se estructura alrededor de los valores fundamentales ligados a la vida, a su cuidado, al trabajo, a las relaciones cooperativas y a la cultura de la justicia, la solidaridad y la paz, un lugar donde encontremos un modo de ser, una manera de estar en el mundo y de relacionarnos armónicamente con los hombres y con la naturaleza.

Es evidente que la realidad social ha dejado de ser un todo monolítico, para convertirse en un escenario moral de pluralidades morales extrañas entre sí, pero, a pesar de ello, la acción de cuidar sigue siendo tan necesaria como inexcusable para la realización del ser humano y ello significa que es fundamental encontrar, más allá del pluralismo axiológico, los fundamentos de una ética compartida tácitamente por los distintos seres humanos.

La experiencia ética se relaciona directamente con la experiencia del deber (Kant, traducido en 1991) y con la experiencia de la felicidad (Aristóteles, traducido en 2007), pero ambas se comprenden en el marco de la experiencia de la alteridad (Emmanuel Lévinas, en Llewelyn, 1999). La ética trata del deber que el hombre tiene respecto a los otros seres humanos y respecto a la naturaleza.

La práctica del cuidar se relaciona, pues, intrínsecamente, no sólo con el deber moral, sino con la esperanza de felicidad. Como Aristóteles (traducido en 2007) apuntaba en sus textos morales, todos los hombres, por naturaleza, desean la felicidad, es decir, la plenitud.

El filósofo que más ha reflexionado sobre la interconexión entre libertad, alteridad y la responsabilidad es Hans Jonas (traducido en 2001). Para él, la ética arranca de un hecho: el hombre es el único ser conocido que tiene responsabilidad. Sólo los humanos pueden escoger 
consciente y deliberadamente entre alternativas de acción y esa elección tiene consecuencias. La responsabilidad emana de la libertad. O, en sus propias palabras: la responsabilidad es la carga de la libertad. La responsabilidad es un deber, una exigencia moral que recorre todo el pensamiento occidental, pero que hoy se ha vuelto más acuciante todavía, porque -en las condiciones de la sociedad tecnológica- ha de estar a la altura del poder que tiene el hombre.

Para Jonas (traducido en 2001), la responsabilidad moral arranca no solamente de una constatación fáctica, la vulnerabilidad de la naturaleza en la era de la técnica; sino también, de un a priori kantiano de respeto a todas las formas de vida.

La ciencia y la técnica han modificado profundamente las relaciones entre hombre y mundo. Para los antiguos, la potencia humana era limitada y el mundo, en cambio, era infinito, él propone el ejemplo de la ciudad griega, que era un enclave civilizado rodeada un entorno amenazador, de bosques y selvas. Pero hoy la situación se ha invertido y la naturaleza se conserva en parques naturales, rodeados de civilización y tecnología. Hoy la naturaleza es débil y está amenazada. El hombre tiene, pues, el deber moral de protegerla y ese deber aumenta en la medida que sabemos lo fácil que es destruir la vida. La ética hoy debe tener en cuenta las condiciones globales de la vida humana y de la misma supervivencia de la especie.

Nacemos, vivimos, crecemos y morimos en un universo radicalmente tecnológico. El entorno familiar, profesional, social, político de nuestras vidas ya no es un entorno natural, virgen o salvaje, sino un entorno artificial, construido por el hombre con su ingenio. La técnica ya no es algo que está ahí, bajo el dominio del ser humano, sino que es nuestro hábitat, nuestro mundo a tal grado que ya no podemos vivir, ni trabajar, ni siquiera distraernos sin la técnica. Para el pensador francés Ellul (1989), reconocido filósofo de la técnica, la técnica representa el fenómeno social más importante del mundo moderno. Según sus atinadas reflexiones, el fenómeno técnico se puede configurar a partir de siete caracteres clave: la racionalidad, la artificialidad, el automatismo de la elección técnica, el autocrecimiento, la individualidad, el universalismo y la autonomía.

Lo que ocurre con la tecnología moderna no es una incompetente conquista de la naturaleza, sino el remplazo del ambiente natural por el ambiente técnico.

La colonización tecnológica del mundo no significa solamente la invasión de artefactos y máquinas en el quehacer de la vida cotidiana y profesional, sino 
que significa la introducción de determinados valores que contaminan actitudes y procedimientos de acción. La colonización tecnológica es también una colonización axiológica, porque se introducen valores nuevos en espacios tradicionales.

"La técnica, dice acertadamente - Scheler - no es, en modo alguno, tan sólo una aplicación posterior de una ciencia puramente contemplativa y teorética que esté determinada tan sólo por la idea de la verdad, la observación, la lógica pura y la matemática pura, sino que es más bien la voluntad de dominación y derivación existente más fuerte o más débil en cada caso y dirigida a este o aquel sector de la existencia, la que contribuye a determinar ya los métodos de pensar y de intuir, pero también los fines del pensar científico" (Sheler, 1973, p. 99).

La responsabilidad en la ética es la articulación entre dos realidades, una subjetiva y otra objetiva. Es forjada por esa fusión entre el sujeto y la acción. Al mismo tiempo, hay también un aspecto de descubrimiento que se revela en la acción propiamente dicha y sus consecuencias. El orden ético está presente no como realidad visible, sino como un llamado sensato que pide calma, prudencia y equilibrio. A esto Jonas (traducido en 2001) lo nombra Principio de responsabilidad.

La responsabilidad del ser humano consigo mismo es indisociable de la que debe tenerse en relación con todos los demás. Se trata de una solidaridad que lo conecta a todos los hombres y a la naturaleza que lo rodea.

Por tanto, resulta innegable que la deducción final de esa reflexión busque atender también lo universal, Jonas establece que "la promesa de la técnica moderna se ha convertido en una amenaza" ( en Mélich, 1998, p. 28) y por ello propone un nuevo imperativo: "Actúa de tal modo que los efectos de tu acción sean compatibles con la permanencia de una vida humana auténtica" o dicho de otro modo: "No pongas en peligro la continuidad indefinida de la humanidad en la Tierra" (en Prieto, 2005, p. 21).

\section{Necesidad de una ética ambiental}

La ética es una parte de la filosofía que trata acerca del bien y del mal desde una base racional. Es una disciplina práctica, según afirma Aristóteles en la ética Nicomaquea, estudiamos ética porque queremos hacernos mejores, no por puro interés teórico. La ética ambiental trata, desde este punto de vista racional, los problemas éticos relacionados con el medio ambiente. Es una ética que cada vez interesa a más teóricos, dado que los problemas ambientales están hoy muy presentes, pues nuestra capacidad de intervención sobre la naturaleza es cada vez mayor. Además, estos problemas no se resuelven con la aplicación de las éticas 
tradicionales, sino que exigen claramente la adecuación de las mismas, un nuevo pensamiento ético. Las líneas de pensamiento que se han ocupado de cuestiones ambientales son básicamente de tres tipos: antropocentrismo fuerte, antropocentrismo moderado y antiantropocentrismo (Bellver Capella,1994).

El antropocentrismo fuerte proclama el primado absoluto del hombre sobre la naturaleza, negando cualquier carácter ético a la relación entre el hombre y el resto de los seres naturales. Por el contrario, el antropocentrismo moderado está fundado sobre la idea de protección y conservación de la naturaleza, y admite que las relaciones del hombre con otros seres naturales pueden tener un carácter ético.

Este planteamiento lo sustenta el filósofo Hans Jonas (1994). Su ética de la responsabilidad reconoce que los vivientes poseen un valor objetivo en función de su capacidad para tener fines. Los fines de los animales superiores son más ricos; en el extremo está el hombre. El ser humano tiene capacidad para proponerse fines conscientemente; además estos fines muy variados están siempre abiertos a la novedad. El valor del ser humano es tal que Jonas (1994) propone como imperativo categórico la preservación de las condiciones de su existencia en un futuro. El ser humano contrae una responsabilidad para con el futuro de la Tierra, de los vivientes y del propio ser humano. De esta responsabilidad deriva una actitud crítica para con la aplicación de nuevas técnicas, cuyas consecuencias pueden poner en peligro el futuro de la Tierra.

Los antiantropocentrismos no se limitan a preocuparse por las consecuencias para la vida humana de las agresiones al ambiente, sino que ponen de manifiesto las profundas relaciones entre todas las partes de la naturaleza, hasta el punto de que entre el sujeto humano y su ambiente no se pueden trazar fronteras definidas. Es la postura Thomas Berry (2009), para quien el hombre es la microfase del cosmos y el cosmos la macrofase del hombre. La prioridad ontológica la tienen las relaciones entre el hombre y el cosmos, pues la naturaleza de las partes está determinada por las relaciones con el todo. El antiantropocentrismo quiere obtener de la ética ecológica una inspiración de carácter general para toda la vida y la cultura (Bellver Capella,

1994). Su aspiración es construir un sistema de valores apto no sólo para la investigación científica y la aplicación de tecnologías, sino también para la política y el derecho en general. Quiere fundar una nueva cultura en sentido amplio, inspirado en las relaciones ecológicas.

\section{Problemas actuales de ética ambiental: Internacionales, Inter- generacionales, Interespecíficos.}


Los problemas ambientales debidos a la extensión de la acción humana son muchos y muy variados. Todos tenemos en mente la disminución de la capa de ozono, la subida de la temperatura media del planeta debido al efecto invernadero, el conflicto de hábitat entre el ser humano y otras especies, y en general, la relación del hombre con los demás seres vivos, la gestión de algunos recursos no renovables, la disminución de los bosques, la gestión de los residuos radioactivos y de todo tipo, la posible contaminación biológica debido a cultivos transgénicos, el establecimiento de generadores de energía como el caso de las refinerías, por citar algunos. Junto con una distribución justa de la riqueza hace falta cada vez más una distribución justa de los riesgos. Cuando se discute sobre la ubicación de una central nuclear se está discutiendo sobre el reparto de los riesgos. Se pueden intentar distintas taxonomías para diferentes fines: prevenir riesgos, distribuirlos con justicia, remediar efectos ya producidos. El economista, el ecólogo, el político, el biólogo, el empresario, el vecino de una fábrica o de un espacio natural protegido, cada uno está interesado a su modo en las cuestiones ambientales y las distribuirá en tipos según su perspectiva. Para la ética, la mejor clasificación es la que pone de manifiesto las relaciones implicadas entre las naciones, entre las generaciones o entre las especies.

Por ejemplo, ¿cómo se debe repartir la disminución de gases de efecto invernadero $\left(\mathrm{CO}_{2}\right)$ ? ¿Quién debería hacer el gasto, los propios países de economías emergentes o los más ricos? Para que la distribución sea justa se requiere una perspectiva general, desde los intereses globales de la humanidad, y no desde los parciales de un determinado grupo o país. Se requiere por tanto un ámbito de discusión, un ámbito legislativo y un poder ejecutivo que estén a la altura de dichos problemas, además del desarrollo de técnicas contables que incorporen la riqueza ambiental, sin las cuales cualquier distribución justa es impensable.

En el caso de los problemas intergeneracionales, es decir, las obligaciones que supuestamente tenemos para con seres humanos que todavía no existen, nos encontramos también con intuiciones fuertes, como por ejemplo, que debemos legar una tierra en buenas condiciones. Para Jonas, el primer imperativo que debe regir nuestra acción es el llamado principio de responsabilidad: "obra de tal manera que no pongas en peligro las condiciones de la continuidad definitiva de la humanidad en la Tierra", o expresado negativamente "Obra de tal manera que los efectos de tu acción no sean destructivos para la futura posibilidad de una vida humana autentica en la Tierra" (Jonas, traducido en 2001, p. 20). Esta ética se basa en el reconocimiento del valor objetivo de los seres vivos, y es precisamente del hombre de quien reclama cuidado. Nuestra primera obligación sería, pues, contribuir a que siga habiendo vida y en especial vida humana sobre la tierra, y que esta vida pueda ser propiamente humana, es decir, que las futuras generaciones de humanos puedan 
atribuirse ambién deberes y consideraciones libres.

En cuanto al tercer tipo de problema, es el que atañe a las relaciones del hombre con otras especies vivas, y con los individuos de otras especies, y con la biosfera en su conjunto, es decir, con seres no humanos. La éticas tradicionales dirimen sobre si los otros seres vivos tienen un valor en sí o solamente un valor utilitario por lo que pueden aportar al hombre. Si le reconocemos valor en sí habría que introducir algún criterio de gradación, criterio que no conduzca por otro lado a pensar que todos los demás seres son iguales al ser humano, pues en la práctica si los otros seres se consideran iguales ontológicamente a los humanos, sería un suicidio, ya que no podríamos alimentarnos ni de plantas ni de animales.

Se impone la introducción de algún criterio que nos permita juzgar el grado de valor de cada ser.

\section{Conclusiones}

La ética del cuidar que aquí tratamos de fundamentar racional y filosóficamente se refiere al cosmos. En la praxis del cuidar, el cultivo de las virtudes es fundamental, pues el cuidar es un ejercicio que requiere unos hábitos y unos caracteres de orden moral. La ética del cuidar demanda una mínima infraestructura racional, unos referentes universales, pero estos referentes no pueden ser principios estáticos, sino modos de acción, formas de interrelación, hábitos, virtudes. Para una ética del cuidar a la altura de las necesidades presentes del universo, no es suficiente el cumplimiento de unos determinados principios mínimos, sino que se pide la vivencia de unos hábitos, de una forma de vida continuada en el tiempo. Por ello, en la ética del cuidar, el punto de partida no son sólo los principios, sino también las virtudes. Según Aristóteles (traducido en 2007) existen dos tipos de virtudes "La dianoética -afirma el Estagirita- se origina y crece principalmente por la enseñanza, y por ello requiere la experiencia y el tiempo; la ética, en cambio, procede de la costumbre" (n. 1103a). No se trata de precisar cuáles son las virtudes dianoéticas y las virtudes éticas en la ética del cuidar, pero sí es preciso afirmar que, para cultivar y desarrollar las virtudes, es posible aprender determinados hábitos o modos de ser mediante la enseñanza, la costumbre o mediante la acción. La educación geocéntrica o planetaria será la que nos ayude a encontrar una relación en armonía con el cosmos. La virtud, propiamente, no es ni una pasión ni una facultad del alma, sino un modo de ser, es decir una manera de estar en el mundo y de relacionarse con los hombres y con la naturaleza.

Los recursos no son infinitos, muchos se están agotando, principalmente el agua y los combustibles fósiles. 
Es necesario tener una actitud solidaria con la Tierra, la vía para conseguirlo es una educación integral, comprometida, humanista, geocéntrica. Se necesitan cambios de hábitos humanos frente al planeta, para que el medio ambiente no sea altamente desfigurado. El antropocentrismo ha considerado al ser humano como rey de la naturaleza, los demás seres tienen sentido si están para su disfrute. Esto rompe con la ley de la solidaridad cósmica. Todos los seres son interdependientes y viven dentro de una intrincadísima red de relaciones. Todos son importantes. El ser humano debe recuperar esa red intrincada de relaciones, para sentirse inmerso en la comunidad planetaria y cósmica. Es necesario recuperar las actitudes de respeto por la naturaleza y los hábitos del cuidado del cosmos.

Para evaluar la importancia de la necesidad de una ética ambiental, hay que tomar conciencia de que nuestra relación con la Tierra, por lo menos en los últimos siglos, está basada en falsas premisas éticas: antropocentrismo fuerte, negación del valor intrínseco de cada ser, dominación de la Tierra, depredación de sus recursos. Tales premisas han producido el actual estado de enfermedad de la Tierra que repercute en la psique humana.

Para tratar la ética ambiental, no toda la tradición filosófica occidental debe ser abandonada, sino desarrollada y puesta al día para afrontar los nuevos problemas ambientales. En el pensamiento de Aristóteles, encontramos que uno de los argumentos a favor de la conservación de las especies será siempre de carácter antropocéntrico, mientras que el respeto a los vivientes individuales puede defenderse también con argumentos biocéntricos. Cada ser vivo tiene un valor propio, objetivo, al margen de su relación con el hombre.

El pensamiento de Aristóteles (traducido en 2007) permite establecer diferentes grados de valor entre los distintos vivientes. "Los individuos vivos son seres en sí mismos, su existencia tiene valor por sí y para sí, objetivamente" (n. 113b). Cada tipo de ser vivo tiene una función ecológica que contribuye al mantenimiento del ecosistema al que pertenece. La idea de mantener una especie por su valor ecológico transfiere a la especie el valor que otorgamos al ecosistema.

La responsabilidad ecológica puede ser asumida sólo por individuos con uso de razón, que poseen los medios que estén a su alcance para evitar la destrucción de la naturaleza. La responsabilidad es proporcional a la capacidad del conocimiento y a la voluntad para decidir y actuar, capacidad que es exclusiva de la especie humana. El hombre, al hacerse consciente 
del universo, reconoce el valor de la propia vida, y el deseo de preservarla y esto es suficiente para generar respeto por la naturaleza. Hans Jonas (2001) propone tres principios para la intervención ecológica: 1) Principio de responsabilidad: obrar con tal responsabilidad frente al entorno, tanto con las actividades humanas como con la toma de decisiones técnicas adoptadas. Preservar la permanente ambigüedad de la libertad del hombre, que ningún cambio de circunstancia puede jamás abolir, preservar la integridad de su mundo y de su esencia frente a los abusos de su poder; 2) Principio de precaución: prevenir todo riesgo de desastre ecológico, yendo incluso mucho más allá de las simples recomendaciones de las leyes vigentes; 3) Principio de transparencia: informar puntual y correctamente, contribuir a la disfunción de las observaciones y hacer aumentar la visibilidad de la información sobre el deterioro ecológico, sus consecuencias y sus remedios.

El mejor camino para crear una conciencia ecológica es la educación, promover que la Tierra es la casa de todos, también es nuestra y debemos preservarla para los demás y para los que vendrán.

La sostenibilidad se traduce en una conducta basada en reutilizar, reciclar, retornar, reparar y reducir el consumo.

Es cierto que una persona con sentido de la fraternidad humana y en comunión con el cosmos es mejor que una persona que carece de ello. Una persona que es capaz de pensar por sí misma sobre cómo vivir y actuar, es mejor que una persona que no ha querido desarrollar esta capacidad, pues el sistema imperante saca de quicio el deseo de tener, a costa de otro deseo más fundamental, que es el de ser y el de elaborar nuestra propia singularidad. Esto exige capacidad de oponerse a los valores dominantes y de vivir ideales ligados a la vida, a su cuidado, a la amistad y al amor.

Urge resucitar el espíritu de mutua pertenencia porque lo perdemos por el exceso de individualismo y de competición que subyacen bajo la crisis actual. Tenemos que alimentar siempre la convicción y la esperanza de que es posible otra relación con la Tierra, más en armonía con sus ciclos y respetando sus límites. Debemos valorar la biodiversidad y a cada ser, vivo 0 inerte, pues todos tienen valor en sí mismos, independientemente del uso humano. Es preciso exigir que las prácticas científicas sean sometidas a criterios éticos a fin de que las conquistas beneficien más a la vida y a la humanidad que al mercado y al lucro. 


\section{FUENTES DE CONSULTA}

- ARISTÓTELES. (2007). La Ética Nicomaquea. (E. Sinnot, Trad.) Buenos Aires: Colihue .

- BELLVER CAPELLA, V. (1994). Ecología: de las razones a los derechos. Granada: Ecorama.

- BERRY, T. (2009). The sacred universe: earth. New York: Columbia University.

- BOFF, L. (2006). Ecología: grito de la tierra, grito de los pobres. Madrid: Trotta.

- DESCARTES, R. (2005). Discurso del método. (A. Hernández, Trad.) Alicante: Club Universitario.

- ELLUL, J. (1989). El siglo XXI y la técnica. Barcelona: Labor.

- FREIRE, P. (1969). La educación como práctica de la libertad. Madrid: Siglo XXI.

- GOLEMAN, D. (1995). Inteligencia emocional. Barcelona: Kairós.

- GÓMEZ, A. (2010). La ética de Sócrates. España: Andres Bello.

- HEIDEGgER, M. (1997). Ser y tiempo. (J. Rivera, Trad.) Santiago de Chile: Universitaria.

- HUSSERL, E. (2009). Lógica formal y lógica trascendental. Ensayo de una crítica de la razón. México: UNAM.

- JONAS, H. (1994). El principio de la responsabilidad. Ensayo de una ética para la civilización tenológica. Barcelona: Círculo de Lectores.

- JONAS, H. (2001). Más cerca del perverso fin y otros diálogos y ensayos. (I. Giner, Trad.) Madrid: Catarata.

- JUNG, C. (1970). Arquetipos e inconsciente colectivo. Madrid: Paidos.

- KANT, M. (1981). Crítica de la razón práctica. Madrid: EspasaCalape.

- LLEWELYN, J. (1999). Emmanuel Lévinas: La genealogía de la ética. (G. Solana, Trad.) Madrid: Ediciones Encuentro.

- LORTZ, J. (2008). Historia de la Iglesia II. Madrid: Ediciones Cristiandad.

- MÉLICH, J. (1998). Totalitarismo yfecundidad. Barcelona: Anthropos.

- MONCADA, J. (2011). Modelo educativo basado en competencias. México: Trillas.

- MONCADA, J. (2011). Tutoria en competencias para el 
aprendizaje autónomo. México: FEP.

- ONU. (2009). Objetivos de desarrollo del Milenio de la Organización de las Naciones Unidas. Nueva York: Departamento de Asuntos Económicos y Sociales de las Naciones Unidas.

- PRIETO, P. (2005). ¿De dónde venimos y para dónde vamos como seres humanos? Bogotá: Instituto de Bioética - Cenalbe.

- ROUSSEAU, J. (1971). Emilio O la educación. Barcelona: Bruguera.

- SHELER, M. (1973). Sociología del saber. Buenos Aires: Soglo $\mathrm{XXI}$.

- SWIMME, B., \& Berry, T. (1986). The universe story. San Francisco: Harpercollins.

- WILSON, E. (2006). La creación: Salvemos la vida en la tierra. Buenos Aires: Kats. 